PERTANIAN

\title{
STUDI TENTANG METODE PERBANYAKAN TANAMAN JERUK SIAM PONTIANAK (Citrus nobilis var microcarpa) SECARA VEGETATIF DI KEBUN PERCOBAAN PUNTEN DESA SIDOMULYO KOTA BATU
}

\author{
Study Of The Propagation Method Of Siamese Pontianak Orange (Citrus nobilis \\ varmicrocarpa) Plant Vegetatively in Experimental garden \\ of Punten Sidomulyo Village Batu City
}

\section{Fenti Margareta*, Budianto dan Sutoyo}

Politeknik Pembangunan Pertanian Malang

email: fentimargareta.stppmalang@gmail.com;082237368079

\begin{abstract}
This research is aimed to find out the most appropriate propagation method of Siamese Pontianak orange plant vegetatively. This research was done on 31st January 2019 until 31st March 2019 in experimentan garden of Punten, Sidomulyo village, Batu City. The method used in propagation of Siamese Pontianak orange planf vegetatively are insert grafting, side grafting, and top grafting. The research method used is Randomized Block Design (RAK) with non factorial experiment method that consist of 3 level that are insert grafting, side grafting, and top grafting that was repeated 9 times, so that obtained 27 experiment units. Data analysis used is ANNOVA and if there is real difference then it will be further tested using BNT. Parameters that are observed are: growing time of shoots, length of shoots, and the number of leaves. The research result show that insert grafting is an appropriate method in propagation of Siamese Pontianak orange plant with better result growing time of shoots, length of shoots, and number of leaves.
\end{abstract}

Keywords: Vegetatif Propagation Method, Siamese Pontianak Orange

ABSTRAK

Penelitian bertujuan untuk mengetahui metode perbanyakan tanaman jeruk Siam Pontianak yang tepat dilaksanakan pada 31 Januari 2019 sampai dengan 31 Maret 2019 di Kebun Percobaan Punten Desa Sidomulyo Kota Batu. Metode yang digunakan dalam perbanyakan tanaman jeruk Siam Pontianak Secara vegetatif yaitu okulasi sisip, sambung samping, dan sambung pucuk. Penelitian ini menggunakan Rancangan Acak Kelompok dengan metode percobaan non faktorial yang terdiri dari 3 taraf yaitu okulasi sisip, sambung samping, dan sambung pucuk yang diulang sebanyak 9 kali, sehingga diperoleh sebanyak 27 unit percobaan. Hasil penelitian menunjukkan bahwa okulasi sisip merupakan metode yang tepat dalam perbanyakan tanaman jeruk Siam Pontianak dengan hasil waktu tumbuh tunas, panjang tunas, dan jumlah daun yang lebih baik.

Kata Kunci: Metode Perbanyakan Vegetatif, Jeruk Siam Pontianak

How to citate: Margareta, F., Budianto dan Sutoyo. 2019. Studi Tentang Metode Perbanyakan Tanaman Jeruk Siam Pontianak (Citrus nobilis var microcarpa) Secara Vegetatif di Kebun Percobaan Punten Desa Sidomulyo Kota Batu. Berkala Ilmiah Pertanian. 2(1): 26-29.

\section{PENDAHULUAN}

Di Indonesia terdapat 3 sistem pembibitan tanaman jeruk. Sistem pertama, seluruh pembibitan dilakukan di lapangan. Sistem kedua, perkecambahan biji batang bawah dilakukan di rumah pembibitan, sedangkan tahapan transplanting sampai bibit siap tanam dilakukan di lapangan. Sistem ketiga, seluruh kegiatan pembibitan dilakukan di rumah pembibitan (Sumeru Ashari, 2006).

Jeruk tergolong kedalam komoditas yang potensial untuk dikembangkan. Kabupaten Banyuwangi merupakan sentral penghasil jeruk terbesar di Provinsi Jawa Timur. Hasil produksi telah diperdagangkan ke seluruh wilayah di Indonesia (Dinas Pertanian Kabupaten Banyuwangi, 2013). Pada tahun 2014 luas panen jeruk di Kabupaten Banyuwangi mencapai 31.984,74 Ha, produksi $663.325,20$ ton dengan produktivitas rata-rata 207,39 Kw/Ha (Badan Pusat Statistik, 2016). Kebutuhan bibit berdasarkan data dapat diperkirakan untuk luasan lahan tersebut mencapai 12.793.896 bibit dengan asumsi kebutuhan bibit 400/Ha.

Perbanyakan tanaman jeruk secara vegetatif adalah perbanyakan dengan menggunakan bahan tanaman selain biji yaitu akar, batang dan daun. Perbanyakan tanaman jeruk dapat dilakukan dengan beberapa metode antara lain: okulasi, sambung pucuk, stek, dan enten. Okulasi sisip merupakan suatu metode yang dilakukan dengan menyayat batang bawah sepanjang $1-2 \mathrm{~cm}$ sehingga kayu dan kulitnya telah diambil yang ukurannya sama besar dengan mata tempel. Sambung samping merupakan metode perbanyakan secara vegetatif yang digunakan apabila diameter batang bawah lebih besar dibandingkan dengan batang atas. Sambung pucuk atau grafting merupakan teknik perbanyakan vegetatif yang dilakukan 
dengan menyambungkan bagian pucuk tanaman yang masih muda sehingga terbentuk gabungan yang dapat hidup terus dan berproduksi (Sumeru Ashari, 2006).

Rumusan masalah dalam penelitian ini adalah metode apa yang paling tepat dalam perbanyakan tanaman jeruk Siam Pontianak secara vegetatif. Sehingga tujuan dilakukannya penelitian ini untuk mengetahui metode perbanyakan tanaman jeruk Siam Pontianak yang tepat.

\section{BAHAN DAN METODE}

Penelitian ini dilaksanakan di Kebun Percobaan Punten Desa Sidomulyo Kota Batu Provinsi Jawa Timur, pada 31 Januari 2019 sampai dengan 31 Maret 2019.

Rancangan yang digunakan adalah Rancangan Acak Kelompok (RAK). Metode kajian yang digunakan adalah metode percobaan non faktorial dengan tiga perlakuan yaitu okulasi sisip, sambung samping, dan sambung pucuk. Setiap perlakuan diulang sebanyak 9 kali, sehingga diperoleh 27 unit percobaan.

Alat dan bahan penelitian yang digunakan antara lain: pisau okulasi, plastik tali, batang bawah, entres, dan alkohol. Batang bawah yang digunakan adalah Japanche citroen (JC) dan batang atas yang digunakan adalah varietas Keprok Siam Pontianak.

\section{HASIL DAN PEMBAHASAN}

\section{Waktu Tumbuh Tunas}

Hasil pengamatan yang telah dilakukan dapat diketahui bahwa pada parameter waktu tumbuh tunas dengan menggunakan metode okulasi sisip (P1), sambung samping (P2), dan sambung pucuk (P3) dapat dilihat pada tabel 1, sebagai berikut:

Tabel 1. Waktu Tumbuh Tunas

\begin{tabular}{ccccccc}
\hline \multicolumn{8}{c}{ Jumlah Tunas Hidup } & \multirow{2}{*}{ Presentase } \\
Perlakuan & \multicolumn{7}{c}{ Hari Setelah Perlakua (HSP) } & Hidup \\
& 1 & 4 & 7 & 10 & 13 & \\
\hline P1 & - & 1 & 5 & 1 & 2 & $100 \%$ \\
P2 & 1 & - & 4 & - & 4 & $100 \%$ \\
P3 & 1 & - & 6 & - & 2 & $100 \%$ \\
Jumlah & 2 & 1 & 15 & 1 & 8 & $100 \%$ \\
\hline
\end{tabular}

Berdasarkan hasil pengamatan yang telah dilakukan, tabel diatas menunjukkan pertumbuhan mata tunas $100 \%$ berhasil pada ketiga perlakuan yang digunakan. Waktu yang diperlukan untuk tumbuh tunas sangat beragam. Setiap perlakuan pada ulangan menunjukkan fluktuasi yang berbeda. Pada hari ke-1 setelah plastik pengikat dibuka, metode sambung samping dan sambung pucuk merupakan metode tercepat untuk tumbuh tunas. Sedangkan pada metode okulasi, waktu tumbuh tunas tercepat yaitu pada 4 hari setelah plastik pengikat dibuka. Kemunculan tunas terlambat terjadi pada 13 hari setelah plastik pengikat dibuka sebanyak 8 tanaman. Rata-rata waktu tumbuh tunas dari ketiga metode yang digunakan terjadi pada 7 hari setelah plastik pengikat dibuka sebanyak 15 tanaman. Keberagaman muncul/pecahnya mata tunas diakibatkan oleh adanya mata tunas yang sedang dalam keadaan dormansi.

Mata tunas yang digunakan pada masing-masing perlakuan harus berasal dari BPMT yang diketahui jelas asal-usulnya. Batang atas harus ditanam dalam screenhouse khusus yang setiap 5 tahun sekali harus dilakukan perombakan untuk pergantian tanaman baru. Mata tunas yang digunakan merupakan mata tunas yang tidak sedang dalam keadaan dormansi yang dapat menghambat pertumbuhannya setelah disambungkan pada batang bawah. Mata tunas yang dapat digunakan hanya bagian tengah saja. Hal ini dikarenakan kandungan nutrisi pada 2 mata tunas bagian bawah sudah disalurkan keatas. Sedangkan 3 mata tunas bagian atas akan cepat mengering jika digunakan untuk okulasi sehingga dapat digunakan untuk sambung pucuk dan sambung samping.

Pertautan antara batang atas dan batang bawah menunjukkan tingkat keberhasilan yang nyata. Keberhasilan metode perbanyakan yang digunakan berdasarkan data hasil kajian pada waktu tumbuh tunas dipengaruhi oleh batang bawah, umur entres, lingkungan, alat yang digunakan, dan keterampilan pelaksana. Menurut Nahansyah (dalam Alamsyah dan Dikayani, 2017) 'perbedaan tingkat kecepatan pecah mata tunas kemungkinan terjadi karena adanya perbedaan kemampuan tanaman untuk membentuk pertautan batang atas dan batang bawah yang berhubungan dengan kecepatan pembentukan jaringan kalus pada kambium'. Sedangkan menurut Hartman (dalam Alamsyah dan Dikayani, 2017) 'menyatakan bahwa dalam pembentukan jaringan kalus diperlukan adanya hormon yang berfungsi untuk pemicu pertumbuhan jaringan dengan memanfaatkan karbohidrat dan gula sebagai pemecah tunas baru'.

\section{Panjang Tunas}

Hasil pengamatan yang telah dilakukan terhadap parameter panjang tunas dapat diperoleh data pada perbanyakan tanaman jeruk secara vegetatif menggunakan metode okulasi (P1), sambung samping (P2), dan sambung pucuk (P3). Data dianalisis menggunakan analisis sidik ragam (ANNOVA) dengan taraf 5\% dan apabila terdapat beda nyata maka di uji lanjut menggunakan BNT. Berdasarkan hasil analisis BNT dapat dilihat pada tabel 2 berikut:

Tabel 2. Hasil Analisis Statistik Parameter Panjang Tunas

\begin{tabular}{|c|c|c|c|c|c|c|c|c|}
\hline \multirow{2}{*}{ Perlakuan } & \multicolumn{8}{|c|}{ Umur (Hari Setelah Perlakuan/HSP) } \\
\hline & 33 & 36 & 39 & 42 & 45 & 48 & 51 & 54 \\
\hline Okulasi Sisip (P1) & 1.24 & 2.73 & 4.41 & 6.81 & 10.13 & 12.22 & $14.24 \mathrm{~b}$ & $15.56 \mathrm{~b}$ \\
\hline Sambung Samping (P2) & 1.13 & 2.67 & 3.68 & 4.9 & 6.33 & 7.58 & $9.22 \mathrm{a}$ & $10.87 \mathrm{a}$ \\
\hline Sambung Pucuk (P3) & 1.52 & 3.28 & 4.32 & 6.58 & 8.32 & 9.47 & $10.3 \mathrm{a}$ & $11.06 \mathrm{a}$ \\
\hline & $\mathrm{TN}$ & $\mathrm{TN}$ & $\mathrm{TN}$ & $\mathrm{TN}$ & $\mathrm{TN}$ & $\mathrm{TN}$ & $\mathrm{N}$ & $\mathrm{N}$ \\
\hline
\end{tabular}

Sumber: Data Primer Diolah 2019

Berdasarkan data analisis statistik menunjukkan kesepadanan yang nyata terhadap laju pertumbuhan panjang tunas pada perlakuan yang digunakan. Pada pengamatan umur $33-48$ hari setelah okulasi, sambung samping dan sambung pucuk, hasil pengamatan menunjukkan bahwa tidak terdapat perbedaan nyata antar perlakuan terhadap panjang tunas. Akantetapi pada umur $51-$ 54 menunjukkan perbedaan nyata pada setiap perlakuan. Data analisis statistik menunjukkan bahwa metode okulasi menghasilkan pertumbuhan rata-rata panjang tunas tertinggi sebesar $15.56 \mathrm{~cm}$. Hal ini disebabkan karena terdapat faktor yang dapat mempengaruhi pertumbuhan. Pada perlakuan sambung pucuk (P3) menunjukkan pertumbuhan tunas tercepat pada awal muncul tunas. Akantetapi pertambahan panjang tunas cenderung perlahan. Sedangkan pada perlakuan okulasi (P1) pertambahan panjang tunas diawal cenderung lambat kemudian laju pertambahan panjang tunas cenderung cepat.

Menurut Haryadi (dalam Alamsyah dan Dikayani, 2017) 'menyatakan bahwa setiap tanaman terdapat perbedaan tingkat respon pemecahan mata tunas oleh adanya pengaruh batang bawah dan interstock dalam mendorong munculnya tunas'. Diduga bahwa kandungan sitokinin yang diproduksi oleh akar dan disalurkan keatas melalui jaringan pembuluh xylem dan asam absisik yang 
disintesis oleh daun muda dalam keadaan yang tidak berimbang sehingga mengakibatkan waktu muncul tunas yang berbeda.

Pertambahan panjang tunas pada batang atas terdapat beberapa faktor yang mempengaruhi. Ditinjau berdasarkan kondisi fisiologi tanaman terdapat gangguan zat pengatur tumbuh (ZPT) dan hasil fotosintesis dalam tanaman. Selain itu umur batang bawah yang terlalu muda dan berkayu dapat menyebabkan kerusakan ketika proses penyambungan, serta umur batang bawah yang terlalu tua akan menyebabkan lambatnya laju pertumbuhan tunas. Pada metode yang paling baik dipengaruhi oleh faktor teknis yaitu hasil sayatan batang atas dan batang bawah yang menunjukkan pertautan melalui proses dua tahap yaitu pembelahan kambium baru dan pembentukan jaringan vaskuler (Yuniastuti et. All., dalam Alamsyah dan Dikayani, 2017).

\section{Jumlah Daun}

Hasil pengamatan yang telah dilakukan terhadap parameter jumlah daun dapat diperoleh data pada perbanyakan tanaman jeruk secara vegetatif menggunakan metode okulasi (P1), sambung samping (P2), dan sambung pucuk (P3). Data dianalisis menggunakan analisis sidik ragam (ANNOVA) dengan taraf 5\% dan apabila terdapat beda nyata maka di uji lanjut menggunakan BNT. Berdasarkan hasil analisis BNT dapat dilihat pada tabel 3 berikut:

Tabel 3. Hasil Analisis Statistik Parameter Jumlah Daun

\begin{tabular}{|c|c|c|c|c|c|c|c|c|}
\hline \multirow{2}{*}{ Perlakuan } & \multicolumn{8}{|c|}{ Umur (Hari Setelah Perlakuan/HSP) } \\
\hline & 33 & 36 & 39 & 42 & 45 & 48 & 51 & 54 \\
\hline Okulasi (P1) & 5.55 & 7.78 & 9.67 & $11.33 \mathrm{~b}$ & $13 \mathrm{~b}$ & $13.89 \mathrm{~b}$ & $14.56 \mathrm{~b}$ & $14.78 \mathrm{~b}$ \\
\hline Sambung Samping (P2) & 4.11 & 5.67 & 6.78 & $7.56 \mathrm{a}$ & $8.34 \mathrm{a}$ & $9.67 \mathrm{a}$ & $10.67 \mathrm{a}$ & $10.78 \mathrm{a}$ \\
\hline Sambung Pucuk (P3) & 6.44 & 8.11 & 9 & $9.78 \mathrm{a}$ & $10.22 \mathrm{a}$ & 10.89 a & $11.56 \mathrm{a}$ & $12 \mathrm{a}$ \\
\hline & $\mathrm{TN}$ & $\mathrm{TN}$ & $\mathrm{TN}$ & $\mathrm{N}$ & $\mathrm{N}$ & $\mathrm{N}$ & $\mathrm{N}$ & $\mathrm{N}$ \\
\hline
\end{tabular}

Sumber: Data Primer Diolah 2019

Berdasarkan hasil pengamatan yang telah dilakukan, seiring pertambahan panjang tunas juga akan diikuti pertumbuhan daun. Hasil analisis pada tabel diatas menunjukkan pada pengamatan 33 - 39 hari setelah okulasi sisip, sambung samping dan sambung pucuk tidak terdapat perbedaan yang nyata antar perlakuan. Pada pengamatan $42-54$ hari setelah perlakuan menunjukkan beda nyata terhadap pertumbuhan jumlah daun. Untuk lebih jelasnya dapat dilihat pada lampiran 4. Berdasarkan tabel diatas menunjukkan bahwa metode okulasi sisip (P1) menghasilkan ratarata jumlah daun tertinggi yaitu 14.777 dan berbeda nyata dengan metode sambung samping dan sambung pucuk. Sehingga pada parameter jumlah daun, okulasi merupakan metode terbaik dalam perbanyakan tanaman jeruk Keprok Siam Pontianak secara vegetatif.

Permulaan munculnya daun (primordia) diawali dengan pembelahan sel-sel tertentu dalam kubah ujung menjadi jaringan meristematik sehingga menghasilkan pembengkakan atau jenggul (protuberances) pada ujung batang. Kemunculan jenggul tersebuat meluas dan melingkari daerah ujung pada primordia pelepah kemudian membentuk leher daun hingga helai daun. Setelah pembentukan leher daun, sel-sel pada subhidermis berubah menjadi meristematik yang dapat menghasilkan tunas ketiak. Kemudian helai daun (lamina), pelepah, dan ruas batang yang berasal dari jaringan meristem yang terdapat diantara jaringan terdiferensiasi (interkalar).

Pertumbuhan daun berbanding lurus dengan panjang tunas, sehingga semakin panjang pertumbuhan tunas maka akan semakin banyak pula pertumbuhan daun oleh proses primordia. Menurut Humphries dan Wheeler (-dalam Gardner, F. P., et. all., 1991) 'menyatakan bahwa jumlah dan ukuran daun dipengaruhi oleh genotip dan lingkungan'. Jumlah daun yang semakin banyak akan berpengaruh pada pertumbuhan tanaman. Hal ini karenakan daun merupakan sebuah organ tanaman yang berfungsi sebagai penyerap dan pengubah energi cahaya menjadi pertumbuhan dan penghasil panen melalui proses fotosintesis (Gardner, et all., dalam Alamsyah dan Dikayani 2017).

\section{KESIMPULAN}

Okulasi sisip merupakan metode terbaik dalam perbanyakan tanaman jeruk Siam Pontianak. Perbanyakan dengan menggunakan metode okulasi sisip menunjukkan waktu tumbuh tunas, pertambahan panjang tunas dan jumlah daun yang lebih baik. Metode okulasi sisip pada perbanyakan tanaman jeruk Siam Pontianak memberikan pengaruh yang nyata pada perlakuan panjang tunas dan jumlah daun.

\section{DAFTAR PUSTAKA}

Alamsyah dan Dikayani. "Percobaan Teknik Chip Budding Pada Tanaman Jeruk"

Ashari, Sumeru. 2006. Hortikultura Aspek Budidaya. Jakarta: UIPress

BPS Kabupaten Banyuwangi. 2016. Luas Panen, Produksi, dan Produktivitas. Banyuwangi

Kushardiyanto, Benny. 2016. Teknik Perbanyakan Tanaman Jeruk (citrus sp) di Balai Penelitian Tanaman Jeruk dan Buah Subtropika. Malang: Universitas Brawijaya

Panduan Teknologi Produksi Benih Jeruk Bebas Penyakit. 2010. Kota Batu: Balitjestro

Pracaya. 2000. Jeruk Manis. Jakarta: Swadaya

P. Gardener, Franklin, et al., 1991. Fisiologi Tanaman Budidaya. Universitas Indonesia: UI-Press

Sarwono, B. 1988. Jeruk dan Kerabatnya. Jakarta: Penebar Swadaya

Sariningtias, N. W., et all. 2014. Penggunaan Benzil Amino Purin (BAP) pada Okulasi Jeruk Keprok (Citrus reticulate). J.Hort.Indonesia. 5(3): 158-167

Soelarso, Bambang. 1996. Budidaya Jeruk Bebas Penyakit. Yogyakarta: Kanisius

Sugiyono. 2015. Metode Penelitian Kuantitatif, Kualitatif, dan R \& D. Bandung: Alfabeta

Suharsi, T. K. dan Sari, A. D. P.2013. Pertumbuhan Mata Tunas Jeruk Keprok (Citrus sp) Hasil Okulasi pada Berbagai Media Tanam dan Umur Batang Bawah Rough Lemon 
(C. jambhiri). Jurnal Ilmu Pertanian Indonesia (JIPI). 18(2): 97-101

Sunarjono, Hendro. 1987. Ilmu Produksi Tanaman Buah-Buahan. Bandung: Sinar Baru

Wudianto, Rini. 1988. Membuat Setek, Cangkok, dan Okulasi. Jakarta: Penebar Swadaya

Yusran dan Noer, A. H., 2011. "Keberhasilan Okulasi Varietas Jeruk Manis Pada Berbagai Perbandingan Pupuk Kandang”. Media Litbang Sulteng. IV (2), 97 - 104 